\title{
PENGEMBANGAN MEDIA PEMBELAJARAN REAKSI KESETIMBANGAN KIMIA
}

\author{
Oleh \\ Luh Joni Erawati Dewi \\ Jurusan Manajemen Informatika, FTK, Undiksha
}

\begin{abstract}
Abstrak
Tulisan ini adalah hasil pengembangan media pembelajaran kesetimbangan kimia dalam bentuk Compact Disc interaktif. Media Pembelajaran Reaksi Kesetimbangan Kimia dibuat untuk membantu proses pemahaman siswa dalam mempelajari kesetimbangan kimia di Sekolah Menengah Atas. Media pembelajaran ini membahas pengertian, jenis dan faktor-faktor yang mempengaruhi pergeseran kesetimbangan. Sistem dikembangkan mulai dari tahap analisis, desain, pengembangan, sampai tahap ujicoba. Untuk proses pengembangannya digunakan Macromedia Flash 8. Dengan adanya Media Pembelajaran Reaksi Kesetimbangan Kimia, diharapkan proses belajar mengajar akan berlangsung lebih menarik, tidak monoton dengan satu media saja.
\end{abstract}

Kata kunci : media pembelajaran, kesetimbangan kimia, pergeseran kesetimbangan

\begin{abstract}
This article is the result of the development of chemical equilibrium instructional media in the form of interactive Compact Disc. Instructional Media of Chemical Equilibrium Reaction was created to assist students in learning process of understanding chemical equilibrium. It discusses about learning media, types and the factors that affect the equilibrium shift. The system was developed following some steps, from analysis, design, develope, and test. For the development process, Macromedia Flash 8 was used. With this equilibrium chemical reaction instructional media, teaching and learning process is expected to be more interesting, not monotonous with just one media.
\end{abstract}

Keywords: instructional media, chemical equilibrium, equilibrium shift 


\section{PENDAHULUAN}

Kesetimbangan kimia (chemical equilibrium) menjelaskan keadaan di mana laju reaksi maju dan reaksi balik dari suatu zat sama besar dan di mana konsentrasi reaktan (zat yang bereaksi) dan produk (zat dari hasil reaksi) tetap tidak berubah seiring berjalannya waktu (Purba, 2007). Kesetimbangan kimia juga mencakup penjelasan terjadinya proses perubahan molekul zat yang dipengaruhi oleh perubahan konsentrasi, tekanan atau volume dari molekul tersebut dan perubahan suhu.

Di dalam menggambarkan alur dari proses perubahan tersebut dibutuhkan suatu pemahaman yang tinggi agar dapat memahami apa dan bagaimana proses itu terjadi. Pembelajaran kimia cenderung harus dibantu dengan praktikum untuk pembuktiannya. Namun, sering terjadi hasil dari sebuah praktikum hanya memberikan gambaran abstrak mengenai perubahan makroskopis dari zat yang bereaksi yang hanya dapat dilihat kasat mata. Untuk mengkaji lebih dalam agar mendapatkan hasil yang lebih nyata mengenai perubahan mikroskopis atau perubahan yang tidak dapat dilihat dengan kasat mata dan tidak dapat diukur yang terjadi pada zat yang bereaksi diperlukan daya imajinasi yang tinggi dan motivasi yang tinggi serta rasa ingin tahu untuk dapat mensimulasikannya sendiri. Dalam memahami hal tersebut terkadang peserta didik merasa jenuh sebab hasil yang didapat terlalu abstrak dan untuk membayangkan proses tersebut perlu sebuah model sebagai gambaran animasi terjadinya perubahan tersebut.

Untuk menangani permasalahan tersebut, diperlukan media pembelajaran alternatif guna membantu proses belajar-mengajar, sehingga motivasi dan pemahaman peserta didik bisa ditingkatkan. Media pembelajaran alternatif yang dimaksud adalah sebagai penunjang proses belajar-mengajar yang menggunakan teknologi komputer.

Berdasarkan uraian di atas, penerapan suatu media dengan model berupa animasi gambar untuk menggambarkan proses mikroskopis yang 
terjadi pada suatu zat sudah merupakan tuntutan. Media pembelajaran reaksi kesetimbangan kimia diharapkan dapat membantu peserta didik lebih memahami dan mengerti terjadinya proses perubahan sistem reaksi kesetimbangan kimia secara mikroskopis akibat pengaruh faktor dari luar sistem kesetimbangan. Oleh sebab itu, akan dikembangkan sebuah media pembelajaran yang mampu menyajikan informasi tidak hanya berupa teks dan gambar, tetapi dilengkapi dengan animasi gambar yang mampu menggambarkan pergerakan mikroskopis yang terjadi dalam ketimbangan kimia.

\section{HASIL DAN PEMBAHASAN}

\subsection{Kesetimbangan Kimia}

Banyak peristiwa dalam kehidupan sehari-hari yang merupakan proses kesetimbangan. Contohnya: perubahan wujud cair, reaksi kesetimbangan dalam tubuh, reaksi kesetimbangan dalam mulut.

Pada umumnya reaksi-reaksi kimia tersebut berlangsung dalam arah bolak-balik (reversible), dan hanya sebagian kecil saja yang berlangsung satu arah. Pada awal proses bolak-balik, reaksi berlangsung ke arah pembentukan produk. Segera setelah terbentuk molekul produk terjadi reaksi sebaliknya, yaitu pembentukan molekul reaktan dari molekul produk. Ketika laju reaksi ke kanan dan ke kiri sama dan konsentrasi reaktan dan produk tidak berubah maka kesetimbangan reaksi tercapai.

Henri Louis Le Chatelier(1884) berhasil menyimpulkan pengaruh faktor luar tehadap kesetimbangan dalam suatu azas yang dikenal dengan azas Le Chatelier sebagai berikut.

"Bila terhadap suatu kesetimbangan dilakukan suatu tindakan (aksi), maka sistem itu akan mengadakan reaksi yang cenderung mengurangi pengaruh aksi tersebut.“

Secara singkat, azas Le Chatelier dapat dinyatakan sebagai:

\section{Reaksi = - Aksi}


Artinya : Bila pada sistem kesetimbangan dinamik terdapat gangguan dari luar sehingga kesetimbangan dalam keadaan terganggu atau rusak maka sistem akan berubah sedemikian rupa sehingga gangguan itu berkurang dan bila mungkin akan kembali ke keadaan setimbang lagi. Cara sistem bereaksi adalah dengan melakukan pergeseran ke kiri atau ke kanan.

\section{Pergeseran kesetimbangan}

Jika pada sistem kesetimbangan diberikan aksi, maka sistem akan berubah sedemikian rupa sehingga pengaruh aksi tadi diupayakan sekecil mungkin. Aksi-aksi yang dapat mempengaruhi terjadinya pergeseraan kesetimbangan antara lain perubahan konsentrasi, perubahan volume, perubahan tekanan, perubahan jumlah mol, perubahan temperatur, dan katalisator.

Dalam pengembangan produk ini akan lebih difokuskan pada tiga faktor saja yaitu pengaruh temperatur, pengaruh konsentrasi, pengaruh tekanan dan volume.

\section{Pengaruh temperatur}

Sesuai dengan azas Le Chatelier, jika suhu atau temperature suatu sistem kesetimbangan dinaikkan, maka reaksi sistem menurunkan temperatur, kesetimbangan akan bergeser ke pihak reaksi yang menyerap kalor (ke pihak reaksi endoterm). Sebaliknya jika suhu diturunkan, maka kesetimbangan akan bergeser ke pihak reaksi eksoterm.

\section{Pengaruh konsentrasi}

Sesuai dengan azas Le Chatelier (Reaksi $=-\mathrm{aksi})$, jika konsentrasi salah satu komponen tersebut diperbesar, maka reaksi sistem akan mengurangi komponen tersebut. Sebaliknya, jika konsentrasi salah satu komponen diperkecil, maka reaksi sistem adalah menambah komponen itu.

\section{Pengaruh tekanan dan volume}

Penambahan tekanan dengan cara memperkecil volume akan memperbesar konsentrasi semua komponen. Sesuai dengan azas Le Chatelier, maka sistem akan bereaksi dengan mengurangi tekanan. 
Sebagaimana diketahui, tekanan gas bergantung pada jumlah molekul dan tidak bergantung pada jenis gas.

Oleh karena itu, untuk mengurangi tekanan maka reaksi kesetimbangan akan bergeser ke arah yang jumlah koefisiennya lebih kecil. Sebaliknya, jika tekanan dikurangi dengan cara memperbesar volume, maka system akan bereaksi dengan menambah tekanan dengan cara menambah jumlah molekul. Reaksi akan bergeser ke arah yang jumlah koefisiennya lebih besar.

\subsection{Pengembangan Media}

Pengembangan produk media pembelajaran ini dimulai dari tahap analisis, desain, pengembangan, sampai tahap ujicoba, seperti terlihat pada Gambar 1. Pada tahap analisis dilakukan pemilihan materi dan penentuan pengguna. Materi yang dimuat dalam media ini adalah pengertian, jenis dan faktor-faktor yang mempengaruhi pergeseran kesetimbangan. Pengguna media adalah siswa Sekolah Menengah Atas Kelas XI. Pada tahap desain, dibuat storyboard dan prototype awal. Storyboard merupakan gambar yang bercerita tentang apa yang ingin disampaikan. Pada tahap tampilan program, dilakukan pembuatan tampilan sesuai dengan storyboard yang sudah dibuat pada tahap desain. Pembuatan tampilan dilakukan dengan Macromedia Flash 8. Pada tahap rekam suara dan editing dilakukan perekaman suara, dan editing kalau diperlukan. Pada tahap mixing dilakukan percampuran tampilan, suara, dan animasi pendukung. Pada tahap ujicoba, dilakukan uji coba terbatas dari ahli isi dan ahli media. Selanjutnya berdasarkan komentar, saran dan masukan dari hasil uji coba, dilakukan evaluasi, dan revisi kalau diperlukan baik tampilan, suara, maupun animasi. 


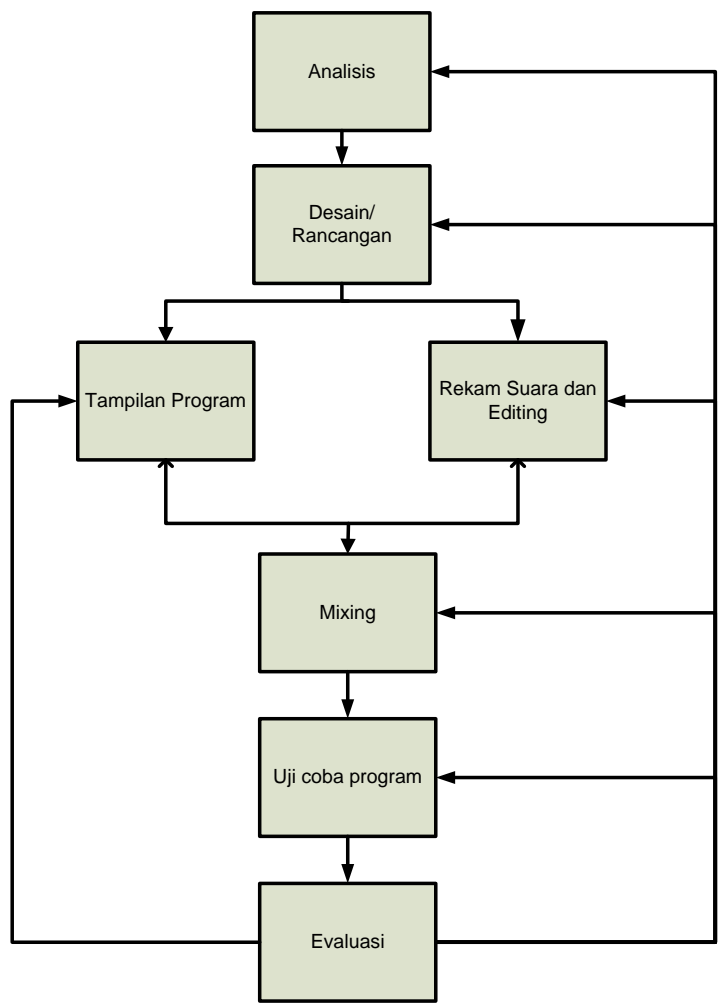

Gambar 1. Langkah Pengembangan Media

Beberapa tampilan media pembelajaran ini dapat dilihat pada Gambar 2 sampai Gambar 5. Pada halaman utama akan tampil pilihan Materi, Latihan, dan Bantuan. Menu materi dibagi lagi menjadi peta konsep, keadaan kesetimbangan, jenis kesetimbangan, tetatan kesetimbangan, pergeseran kesetimbangan dan contoh. Jika pengguna memilih materi peta konsep maka akan tampil hasil seperti terlihat pada Gambar 3. 


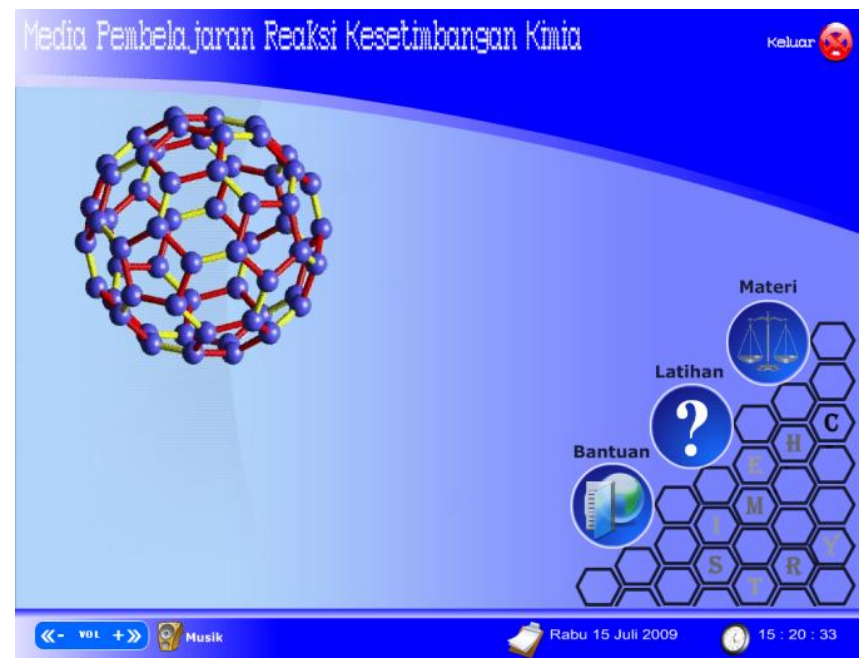

Gambar 2. Tampilan menu utama

Pada materi pergeseran kesetimbangan akan muncul tiga buah menu yaitu pengaruh suhu terhadap kesetimbangan, pengaruh tekanan terhadap kesetimbangan, dan pengaruh penambahan volume pada kesetimbangan. Jika pengguna memilih pengaruh penambahan konsentrasi zat maka akan muncul tampilan seperti terlihat pada Gambar 4.

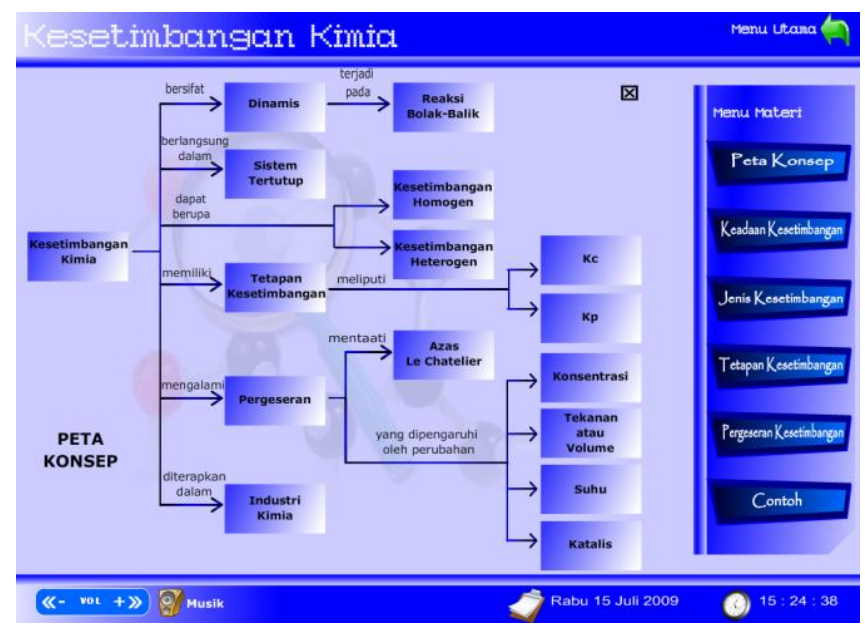

Gambar 3. Tampilan menu peta konsep 


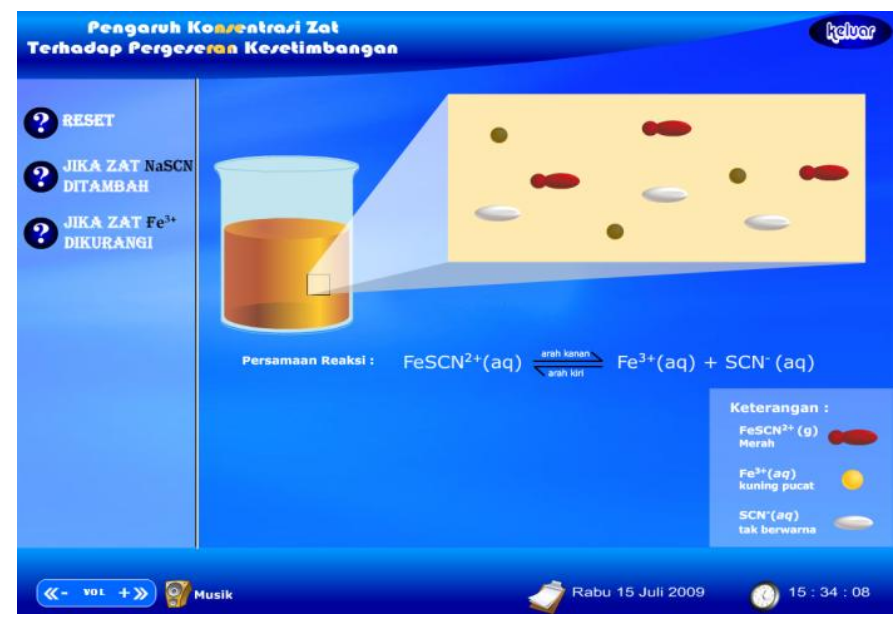

Gambar 4. Tampilan menu pengaruh konsentrasi zat terhadap kesetimbangan

Selain memilih materi, pengguna juga bisa mengukur kemampuannya dengan memilih menu latihan soal. Soal yang disediakan oleh sistem sebanyak 20 buah, dan pertanyaan yang muncul sebanyak 10 soal yang diambil secara acak. Contoh tampilan soal dapat dilihat pada Gambar 5. Setelah sepuluh soal tampil, media akan memberikan skor secara otomatis dan pengguna bisa mengetahui jawaban yang benar dari masing-masing soal beserta pembahasannya.

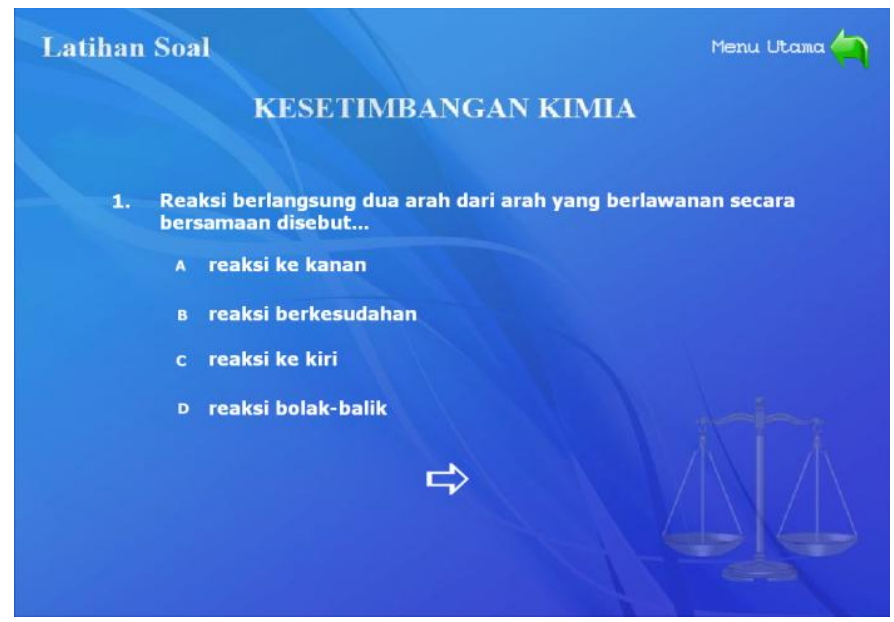

Gambar 5. Menu latihan soal 
Media Pembelajaran Kesetimbangan Kimia ini memuat materi dalam bentuk audio visual. Seperti diungkapkan oleh Edgar Dale dalam Arsyad, 2009, bahwa bahan-bahan audio visual dapat memberikan banyak manfaat asalkan guru berperan aktif dalam proses pembelajaran. Hubungan guru siswa tetap merupakan elemen penting dalam sistem pendidikan modern saat ini. Guru harus selalu hadir untuk menyajikan materi pelajaran dengan bantuan media apa saja.

\section{PENUTUP}

Telah berhasil dibuat sebuah media pembelajaran reaksi kesetimbangan kimia dengan menggunakan Macromedia Flash 8 dan Adobe Photoshop CS2 yang digunakan untuk pengolah gambar dan animasi, serta Cool Edit Pro 2.0 yang digunakan untuk pengolah suara.

Media pembelajaran reaksi kesetimbangan kimia merupakan media pembelajaran yang dikemas dalam bentuk Compact Disc interaktif, yang memberikan informasi mengenai pengertian reaksi kesetimbangan kimia, faktor-faktor yang mempengaruhi pergeseran kesetimbangan dan bagaimana akibat dari pengaruh faktor tersebut serta arah reaksi kesetimbangan pada gerak mikroskopis atau gerak yang tidak dapat dilihat dengan kasat mata. Dengan penggunaan media pembelajaran ini diharapkan bisa memudahkan pengguna di dalam mempelajari dan memahami proses terjadinya reaksi kesetimbangan dan pergeseran kesetimbangan serta gerak mikroskopis suatu zat dalam sistem yang berkesetimbangan.

\section{Daftar Pustaka}

Arsyad, A. 2009. Media Pembelajaran. Jakarta: PT. Raja Grafindo Persada 
Nasrudin, H. 2004, Kesetimbangan Kimia, tersedia pada http://darto.fileave.com/kesetimbangan_kimia.pdf, tgl akses 20 Februari 2009

Purba, M. 2007. Kimia untuk SMA Kelas XI. Jakarta: Erlangga 